\title{
Middlebrook 7H10 Growth Medium
}

National Cancer Institute

\section{Source}

National Cancer Institute. Middlebrook 7 H10 Growth Medium. NCI Thesaurus. Code C85509.

A solid growth medium that was developed specifically for the primary and secondary cultivation of mycobacterium and for detection of the mycobacterium's sensitivity to antimicrobial agents. 